\title{
Screening of iron-enriched fungus from natural environment and evaluation of organically bound iron bioavailability in rats
}

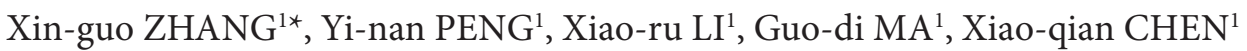

\begin{abstract}
Iron is an essential element for nearly all living organisms, and its deficiency is the most common form of malnutrition in the world. The organic forms of trace elements are considered more bioavailable than the inorganic forms. Although Saccharomyces cerevisiae can enrich metal elements and convert inorganic iron to organic species, its tolerability and transforming capacity are limited. The aim of this study was to screen higher biomass and other iron-enriched fungi strains besides Saccharomyces cerevisiae from the natural environment. A PDA medium containing $800 \mu \mathrm{g} / \mathrm{mL}$ iron was used for initial screening. Fifty strains that tolerated high iron concentration were isolated from the natural environment, and only one strain, No.BY1109, grew well at Fe (II) concentration of 10,000 $\mathrm{g} / \mathrm{ml}$. According to morphological characterization, $18 \mathrm{~S}$ rDNA sequence analysis, and biophysical and biochemical characterization, the strain No.BY1109 was identified as Rhodotorula. The iron content of No.BY1109 (10 mg Fe/g dry cell) was determined using atomic absorption spectrometry. The results of distribution of iron in the cells showed that iron ion was mainly chelated in the cell walls and vacuoles. The bioavailability in rats confirmed that strain No.BY1109 had higher absorption efficiency than that of ferrous sulfate after single dose oral administration. The present study introduces new iron supplements, and it is a basis for finding new iron supplements from natural environment.
\end{abstract}

Keywords: iron-rich fungus; screening and isolation; identification; cell-iron distribution; bioavailability.

Practical Application: Iron is an essential element for nearly all living organisms, and its deficiency is the most common form of malnutrition in the world. The present study described the higher bioavailability of iron from natural environment grown in high iron medium. The result is interesting and shows some new data for finding new iron supplements from natural environment.

\section{Introduction}

Iron is an essential element for nearly all living organisms (Abbaspour et al., 2014). It is a key functional component for oxygen transport and storage molecules and for many enzymes that catalyze the redox reactions required for the generation of energy, the production of various metabolic intermediates, and host defense (Conrad \& Umbreit, 2000).

Iron deficiency (ID) and iron deficiency anemia (IDA) are serious public health problems throughout the life cycle in both industrialized and developing countries (Sirdah et al., 2014). According to the World Health Organization (WHO), iron deficiency is one of the most prevalent nutrient deficiencies in the world, affecting an estimated two billion people worldwide. Approximately $30 \%$ of the world's population are iron deficient with variable prevalence, distribution, and contributing factors in different parts of the world (Santiago 2012; Miller, 2013).

Oral iron therapy is the most widely prescribed treatment for ID and IDA; however, the major challenges in the management of IDA are related to the tolerability and side effects of iron therapy in its different forms (Ruiz-Argüelles 2013). The most widely prescribing oral iron is mainly composed of ferrous salts, which are characterized by low and variable absorption rates
(Khalafallah \& Dennis 2012). Therefore, it is crucial to find the most appropriate form of iron and determine the duration of treatment in order to successfully replenish iron stores.

Due to its ability to incorporate metals, yeast biomass has been used as a delivery vehicle for many mineral supplements. Under appropriate conditions, S. cerevisiae can accumulate large amounts of trace elements, such as selenium, manganese, copper, zinc, and iron, and incorporate them into organic compounds (Rayman, 2004; Stehlik-Tomas et al., 2004; Pas et al., 2007; Yuan et al., 2004). Previous studies found that healthy volunteers or infants supplemented with Se-enriched yeast (Rayman, 2004), Zn-enriched yeast (Tompkins et al., 2007), and iron enriched yeast (Liu et al., 1990), were more significantly affected by supplementation with trace elements-enriched yeast than that of inorganic supplementation. Thus, yeast biomass enriched with trace elements can be a new and safer solution to prevent trace element deficiencies since it is more easily absorbed by the human body.

Studies on the processes involved in the uptake of trace metals by $S$. cerevisiae yeast have increased considerably in recent years. S.cerevisiae has become a model microorganism for 
studying metal transporters and accumulation in cells (Nelson, 1999). Mammalian cells require sufficient amounts of iron to satisfy metabolic needs or to accomplish specialized functions. Iron is an essential but potentially hazardous biometal (Wang \& Pantopoulos, 2011), and it profoundly affects biological systems because it is toxic or harmful when present in excessive amounts (Wysocki \& Tamás, 2010). Therefore, wild-type S. cerevisiae strains cannot grow on high-iron media, and its ability to accumulate inorganic iron is limited.

Fungi have a worldwide distribution and grow in a wide range of habitats, including extreme environments such as deserts or areas with high salt concentrations. Therefore, it is possible that in the natural environment there are strains with higher tolerance to inorganic iron and higher ability of converting and accumulating iron than that of $S$. cerevisiae wild-type strain. Despite the importance of studies on novel organic iron supplements possessing lower toxicity and higher efficiency, to our knowledge, few comparative studies on the organic bound-iron supplements obtained from the nature have been reported. The present study aimed to screen high-biomass fungi strains with better accumulation of high concentration iron than that of S. cerevisiae isolated from natural environments and to compare their bioavailability in rats using ferrous sulfate.

\section{Materials and methods}

\subsection{Samples collection}

The soil samples (approximately $50 \mathrm{~g}$ ) were collected $5-10 \mathrm{~cm}$ below soil surface, in paper bags, from different sites in an iron mine in Baiyin district, Gansu province, China.

\subsection{Chemicals and media}

All chemical reagents were of analytical or higher grade. Martin medium: 0.003\% Rose Bengal, 0.1\% $\mathrm{KH}_{2} \mathrm{PO}_{4}$, $0.05 \% \mathrm{MgSO}_{4} 7 \mathrm{H}_{2} \mathrm{O}, 0.5 \%$ peptone, $0.1 \%$ yeast extract, $1 \%$ glucose and $0.003 \%$ Streptomycin sulfa ( $\mathrm{pH} 7.0$ ). YPD medium: $1 \%$ yeast extract, $2 \%$ peptone and $2 \%$ glucose. Media were solidified by adding $2 \%$ agar when required.

\subsection{Screening and isolation of microorganisms}

In a $500 \mathrm{ml}$ Erlenmeyer flask, $100 \mathrm{ml}$ of Martin medium was inoculated with $1 \mathrm{~g}$ soil sample containing $800 \mu \mathrm{g} / \mathrm{ml} \mathrm{Fe}$ (II) solutions which $\mathrm{FeSO}_{4}$ dissolved in deionized water and sterilized using a $0.45 \mu \mathrm{m}$ filter membrane. The culture was incubated at $30^{\circ} \mathrm{C}$ at $200 \times \mathrm{g}$ in a rotary shaker for 7 days. There was no change in the entire colony diameter by the fifth day, and the strains were incubated for 5 days in subsequent studies. This process was repeated with successively higher concentrations of Fe (II) solutions $(2,000,4,000,6,000$, and $8,000-10,000 \mu \mathrm{g} / \mathrm{ml})$ until the minimum inhibitory concentration (MIC) of each isolate was obtained. The response of the microorganisms to various concentrations of Fe (II) solutions was assayed by growing pure cultures on Martin medium. Agar discs $(90 \mathrm{~mm})$ from the actively growing colonies were used to inoculate the center of Martin agar medium dishes.

\subsection{Determination of Iron content of microorganism cells}

Grown cells in suspension were collected by centrifugation, washed repeatedly, dialyzed until no free iron ion was observed in the deionized water, dried to a constant weight at $60^{\circ} \mathrm{C}$, and weighed as biomass which was defined as the cell weight per $100 \mathrm{ml}$ of culture broth. The dried cells were digested with a $14 \mathrm{M}$ nitric acid $10 \mathrm{M}$ perchloric acid mixture (4:1, v/v) by boiling until a clear solution was obtained. The concentration of iron was determined by atomic absorption spectrometry (Bağ et al., 1998).

\subsection{Identification of fungus}

\section{Morphological characteristic}

The isolated fungus was grown on Martin medium. Cell morphology was evaluated using a microscope (Motic E220, China).

\section{$18 S$ rDNA sequence analysis}

The genomic DNA was extracted using glass beads for cell disruption. Cells were suspended in $400 \mu$ l of lysis buffer $100 \mathrm{mM}$ Tris- $\mathrm{HCl} \mathrm{pH}$ 8.0, 1.0\% SDS, 2.0\% triton X-100, 10mM EDTA, $100 \mathrm{mM} \mathrm{NaCl}$ ) and vortexed for $5 \mathrm{~min}$. After adding $400 \mu \mathrm{l}$ of phenol: chloroform: isoamy alcohol (P/C/I; 25:24:1), $400 \mathrm{mg}$ of glass beads ( $0.5 \mathrm{~mm}$ in diameter) were added to disrupt the cells. The samples were mixed vigorously for $15 \mathrm{~min}$, centrifuged at $20,000 \times \mathrm{g}$ for $10 \mathrm{~min}$, and the aqueous layer was then collected. It was extracted once with an equal volume of $\mathrm{C} / \mathrm{I}$. The sample was precipitated with one volume of cold isopropyl alcohol and centrifuged at $20,000 \times \mathrm{g}$ for $10 \mathrm{~min}$. The DNA was washed with $70 \%$ ethanol, air-dried, resuspended in $100 \mu$ of Tris EDTA (10mM Tris- $\mathrm{HCl}, 1 \mathrm{mM}$ EDTA $\mathrm{pH} 8.0)$, and stored at $-20^{\circ} \mathrm{C}$ (Yamada et al., 2002).

The 18S rDNA from the extracted DNA was amplified by PCR using primer 2234C (5'-GTTTCCGTAGGTGAACCTGC-3') and primer 3126T (5'-ATATGCTTAAGTTCAGCGGGT-3'). The reaction mixtures were composed of $5 \mu \mathrm{l} 10 \times \mathrm{PCR}$ buffer, $0.2 \mathrm{mM}$ dNTPs, $1 \mu \mathrm{Mol}$ each primer, $5 \mu \mathrm{l}$ DNA template, 2.5 units Taq DNA polymerase, and the sterile deionized water added to a final volume of $50 \mathrm{ml}$.

PCR profile was as follows: initial denaturation at $94^{\circ} \mathrm{C}$ for $3 \mathrm{~min}$, followed by 25 cycles of denaturation $\left(94^{\circ} \mathrm{C}, 1 \mathrm{~min}\right)$, annealing $\left(50^{\circ} \mathrm{C}, 45 \mathrm{sec}\right)$, extension $\left(72^{\circ} \mathrm{C}, 2 \mathrm{~min}\right)$, and final extension at $72^{\circ} \mathrm{C}$ for $10 \mathrm{~min}$. DNA sequences were performed by Sangon Biotech, Inc. (China) The 18S rDNA gene sequences were determined by a BLAST search against GenBank database (http://www.ncbi.nlm.nih.gov/). The sequences determined and reference sequences downloaded from GenBank Database were aligned using the multiple-sequence alignment software CLUSTAL X version 1.81. Phylogenetic trees were constructed with the molecular evolutionary genetics analysis software MEGA version 3.1. The nucleotide sequences of the high-iron strain $18 \mathrm{~S}$ rRNA gene reported in this study are available at the GenBank database (accession numbers JN886089). 


\section{Biophysical and biochemical characteristics}

The temperature and $\mathrm{pH}$ of the isolate were determined by measuring the biomass. The temperature profile was tested at $16-42^{\circ} \mathrm{C}$. The $\mathrm{pH}$ profile was tested at a $\mathrm{pH}$ range from 4.0 to 9.0. Incubations were carried out at $30^{\circ} \mathrm{C}$ at $200 \times \mathrm{g}$ for 5 days on YPD medium.

The strain incubated on YPD medium inoculated with inoculums were maintained at a concentration of $8,000 \mu \mathrm{g} / \mathrm{ml} \mathrm{Fe}$ (II) solutions. The flasks were incubated at $30^{\circ} \mathrm{C}$ at $200 \times \mathrm{g}$ and $1 \mathrm{ml}$ of broth was withdrawn from the tubes at regular intervals of 0 , $6,12,18,24,30,42,48,54,60,66,72,78$, and $84 \mathrm{~h}$. Absorbance was measured at $600 \mathrm{~nm}$ using a spectrophotometer (UV-9200, china).

The following tests were conducted: starch hydrolysis, catalase test, tyrosine hydrolysis, casein hydrolysis, gelatin liquefaction test, urease test, citrate utilization test, litmus milk test, glucose fermentation test, nitrate reduction test and carbon source utilization test. All tests were proposed by $\mathrm{Hu}$ (2004) and Barnett et al. (2000). And Escherichia coli were used as the negative control and bacillus subtilis as the positive control. The strain was deposited in the Center of Industrial Culture Collection, Gansu, China (collection number GSICC 51805).

\section{Bioavailability of bound iron from fungi}

All animals used in the present research were well cared following the regulations of the Association for Accreditation of Laboratory Animal Care (AAALAC). Normal female Wistar rats $(250 \pm 10 \mathrm{~g})$, purchased from Laboratory animal center of Lanzhou University, were housed in a temperature-controlled room at $23 \pm 1^{\circ} \mathrm{C}$. Rats were fed a standard laboratory diet and were given deionized water.

Rats were divided into two groups at random; the control group was treated with ferrous sulfate tablets, and the experimental group was treated with high-iron enriched rich fungus. The high-iron enriched fungi which were collected by centrifugation at $4000 \mathrm{~g}$ for $15 \mathrm{~min}$, washed, and dialyze until no free iron ions were observed in the deionized water. The rats were fasted overnight for $12 \mathrm{~h}$ before the experiment. Each rat received intragastric administration of Fe (II) at a dose of $10 \mathrm{mg} / \mathrm{Kg}$ body weight. Whole blood samples were periodically taken from fundus vein before and after oral administration at $0,5,15,30,45,60,90,120$, and $180 \mathrm{~min}$.

Blood samples were treated with $14 \mathrm{M}$ nitric acid $10 \mathrm{M}$ perchloric acid mixture $(4: 1, \mathrm{v} / \mathrm{v})$ by boiling until a clear solution was obtained. The content of iron was determined using atomic absorption spectrometry (AAS-3200, Shanghai, China) (Bağ et al., 1998).

\section{Data analysis}

Pharmacokinetic parameters of bound iron were calculated by non-compartmental and compartmental methods using the MCPKP software. The maximum plasma concentrations (Cmax) and the time to reach the maximum concentrations (Tmax) were obtained directly from the observed data. The elimination half-life $\left(t_{1 / 2}\right)$ was calculated using $0.693 / \mathrm{kel}$, and the elimination rate constant (kel) was obtained from the slope of terminal portion of the log-linear terminal portion of the plasma concentration versus time curve by linear regression. The area-under-curve was calculated by the trapezoidal rule. Bioavailability was calculated according to the following equation: Bioavailability $=$ AUCtest/AUC Ferrous Sulfate $\times 100 \%$. All results were expressed as arithmetic mean \pm standard deviation (SD).

\section{The distribution of iron in cells}

Cell walls were isolated by the method of Kollár et al. (1997) and Dallies et al. (1998). Vacuoles, cytosol, mitochondrial fractions were prepared by Raguzzi et al. (1988). Cell membranes were obtained according to Yamaguchi-Iwai et al. (1995). Total RNA was prepared according to Mutiu \& Brandl (2005), and total DNA was prepared following the method proposed by Fredricks et al. (2005). DNA and RNA concentrations were measured spectrophotometrically.

\section{Results}

\subsection{Screening and Isolation of microorganisms}

The soil samples from natural environment (Baiyin District, Gansu Province) were inoculated on Martin medium supplemented with $800 \mu \mathrm{g} / \mathrm{ml} \mathrm{Fe}$ (II) solutions; fifty morphologically different colonies were found to grow well in this medium. With a gradual increase in the selective metal pressure in PDA medium, four colonies that tolerated $8000 \mu \mathrm{g} / \mathrm{ml} \mathrm{Fe}$ (II) were found. One isolate was capable of growth at concentrations of $10000 \mu \mathrm{g} / \mathrm{mL} \mathrm{Fe}$ (II) and was designated as No.BY1109.

\subsection{Identification of microorganisms}

In biology, morphology is a branch of bioscience dealing with the study of the form and structure of organisms and their specific structural features. Morphological characteristic of strain No.BY1109 is shown in Figure 1. The colonies grow rapidly on Martin medium and are pink, smooth, and glistening and had and ellipsoidal or spherical shape.

The $18 \mathrm{~S}$ rDNA sequence was a convenient and universal marker for fungal species identification. The result of the partial $18 \mathrm{~S}$ rDNA region of strain No.BY1109 alignment based on BLAST analysis revealed that the isolate was identified as Rhodotorula. A phylogenetic tree was constructed using maximum-parsimony and neighbour-joining with MEGA 5.0 software (Figure 2). The numbers at the Nodes indicate the levels of bootstrap support, based on a neighbor-joining analysis of 1,000 resample datasets; only values $>50 \%$ are indicated. The Bar represents 0.05 substitutions per nucleotide.

The topology of the tree was evaluated using a bootstrap analysis with 1000 replications. The highest $18 \mathrm{~S}$ rRNA sequence similarities between the isolate and type strains of recognized species in the databases were $99 \%$.

\subsection{Biophysical and biochemical characteristics}

The effect of temperature and $\mathrm{pH}$ of the No.BY1109 strain growth were investigated on YPD. Figure 3 a shows the optimal growth of the strain No.BY1109 at pH 6.0-7.0. The strain grew 

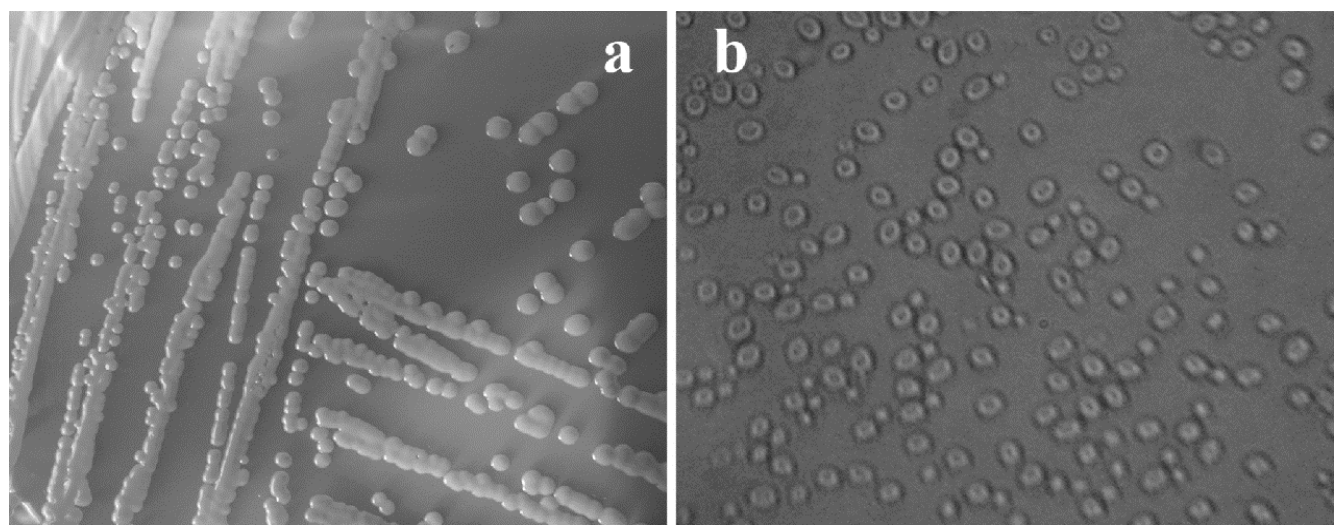

Figure 1. Morphological characteristic of strain No.BY1109; Figure 1a and Figure 1b show the colonies and Microscopic image of BY- 1109 grown on Martin medium at $30^{\circ} \mathrm{C}$ for 3 days.

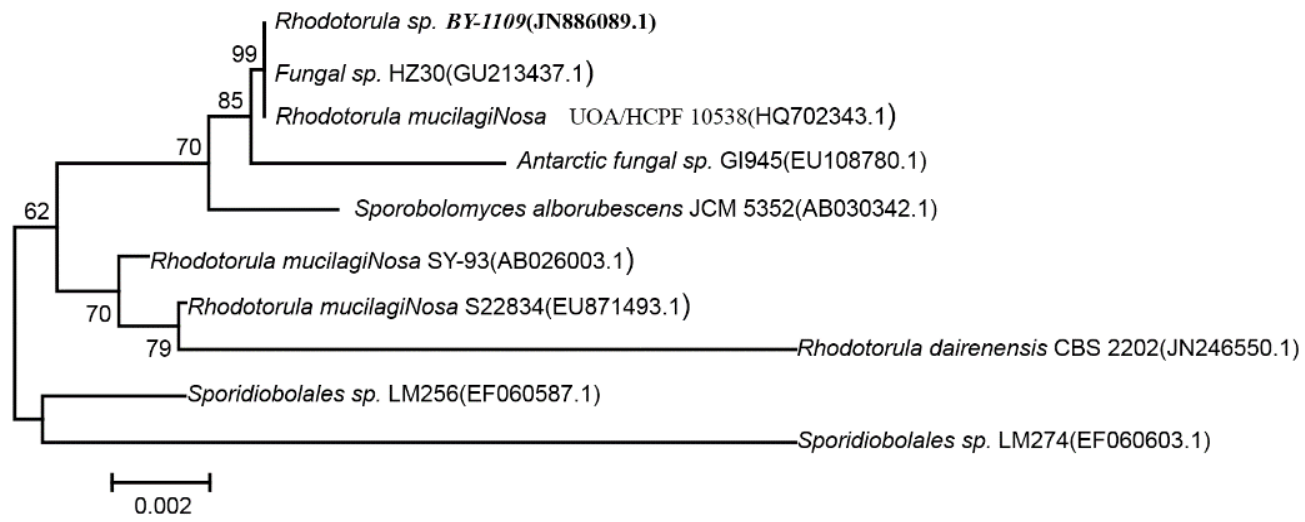

Figure 2. Phylogenetic dendrogram based on 18SrRNA gene sequences showing relationships between strain No.BY1109 and representatives of the genus Rhodotorula.
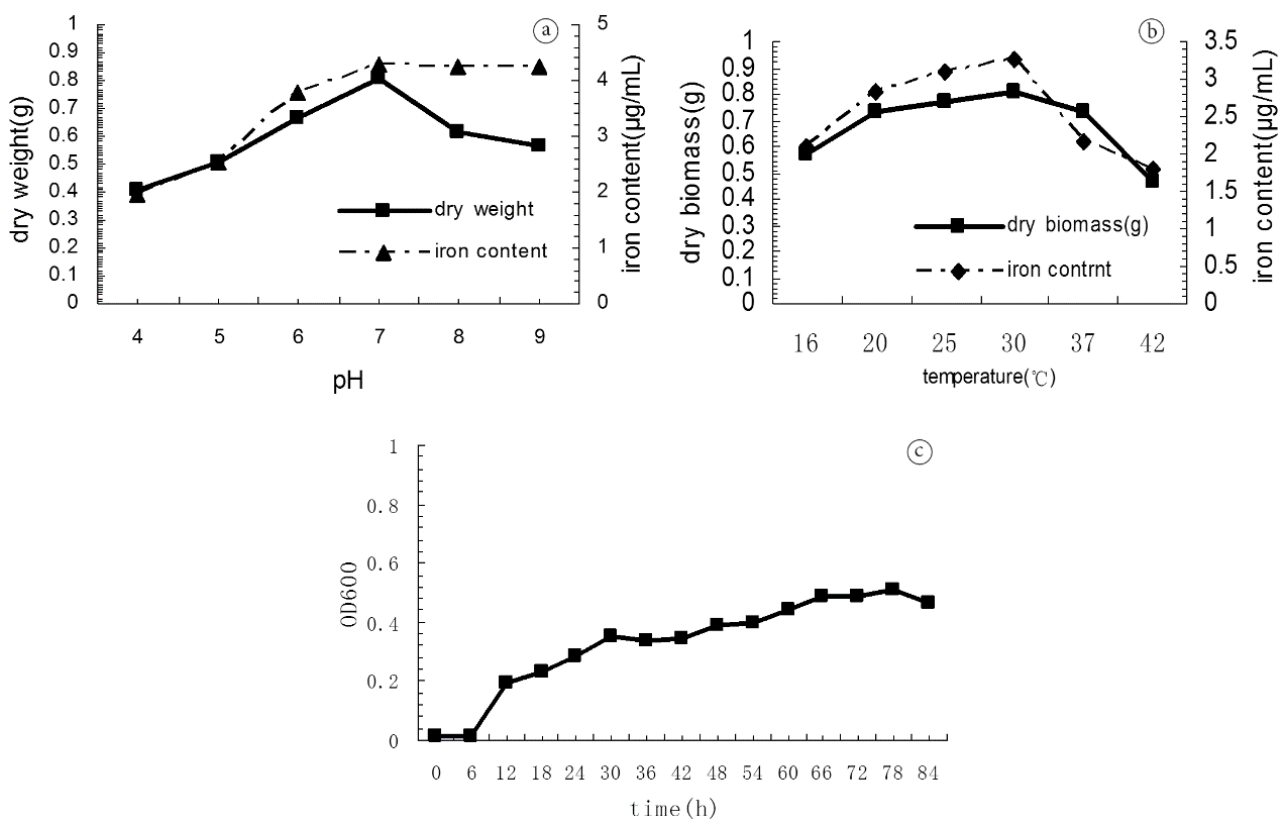

Figure 3. Influence of different $\mathrm{pH}$ and temperature on the biomass and iron content of No.BY1109. Figure $3 \mathrm{a}$ and $3 \mathrm{~b}$ show $\mathrm{pH}$ and temperatures after incubation at $30^{\circ} \mathrm{C}$ for 3 days, respectively, and Figure $3 \mathrm{c}$ shows the growth curve of No.BY1109 at concentration of $8,000 \mu \mathrm{g} / \mathrm{ml}$ Fe(II) on YPD medium. 
well in a wide range of temperature $\left(16-42^{\circ} \mathrm{C}\right)$, and the optimum growth and was observed at $30^{\circ} \mathrm{C}$ (Figure $3 \mathrm{~b}$ ). The broad range of $\mathrm{pH}(4.0$ to 9.0$)$ and temperature tolerance $\left(20^{\circ} \mathrm{C}\right.$ to $\left.35^{\circ} \mathrm{C}\right)$ were considered promising in terms of suitability of this fungal strain for possible future application in a wide range of geographical locations. The higher conversion of iron was observed at the optimum growth $\mathrm{pH}$ and temperature.

The growth curve of the No.BY1109 exhibited typical twophase character with prolonged stationary phase, probably due to the ability of the yeast cells to utilize lipid storages formed during growth as additional energy source and the best incubation condition was 3 days (Figure 3c).

Physiological and biochemical properties are summarized in Table 1. In addition, identical biochemical reactions were recorded for both organisms examined (Table 1). Positive reactions for glucose, myoinositol, and urease activity were obtained. Negative reactions were observed for Litmus milk test, Glucose fermentation test, Nitrate reduction test, and Gelatin liquefaction test.

\subsection{Influence on the biomass and iron content of microorganism}

It is well known that iron ion (II) inhibits the growth of microorganism. In order to determine the toxicity of Fe (II) and to obtain high-iron and high-biomass microorganism, it was necessary to choose the optimal $\mathrm{Fe}$ (II) ion concentrations in the medium. Figure 4 shows that No.BY1109 had the highest biomass and cell-iron content at concentration of $8,000 \mu \mathrm{g} / \mathrm{ml} \mathrm{Fe}$ (II).

\subsection{Bioavailability}

The pharmacokinetic parameters were determined to compare iron absorption, and the plasma concentration-time curve is shown in Figure 5. The pharmacokinetic parameter results, obtained using the MCPKP software, are shown in Table 2, and the bioavailability of No.BY1109 in rats was analyzed. The drug concentration-time data fit well to a one-compartment model after oral administration. The area under the plasma concentrationtime curve (AUC) and the maximum iron blood concentration (Cmax) of No.BY1109 and ferrous sulfate tablets were 286360 and $239570 \mathrm{mg} / \mathrm{l} . \mathrm{min}, 901.27 \mu \mathrm{g} / \mathrm{ml}$ and $850.93 \mu \mathrm{g} / \mathrm{ml}$, respectively.

\subsection{Distribution of iron in cells}

The cells were grown in an YPD medium containing $8,000 \mu \mathrm{g} / \mathrm{mL}$ Fe (II), and the iron content in cell walls, vacuolar, cell membranes, mitochondrial fractions, and DNA and RNA were determined and shown in Table 3. In the cells grown in the medium containing $8,000 \mu \mathrm{g} / \mathrm{mL}$ Fe (II), the iron content was significantly higher than that in the No.BY1109 cells grown in the medium without $\mathrm{Fe}$ (II), particularly in cell walls, vacuoles and cytosolic. This indicates that inorganic iron in medium was incorporated into the cells and was converted into organic iron compounds, which mainly existed in cell walls and vacuoles.
Table 1. Biophysical and biochemical characteristics of No.BY1109.

\begin{tabular}{cc}
\hline Components and tests & No.BY1109 \\
\hline Glucose & + \\
Sucrose & + \\
Maltose & + \\
L- Arabia sugar & + \\
Raffinose & + \\
Sorbitol & + \\
Starch & + \\
Inositol & + \\
Starch hydrolysis & - \\
Catalasetest test & + \\
Tyrosine hydrolysis & + \\
Casein hydrolysis & - \\
Gelatin liquefaction test & - \\
Urease test & + \\
Citrate utilization test & - \\
Litmus milk test & - \\
Glucose fermentation test & - \\
Nitrate reduction test & -
\end{tabular}

(+) positive; (-) negative.

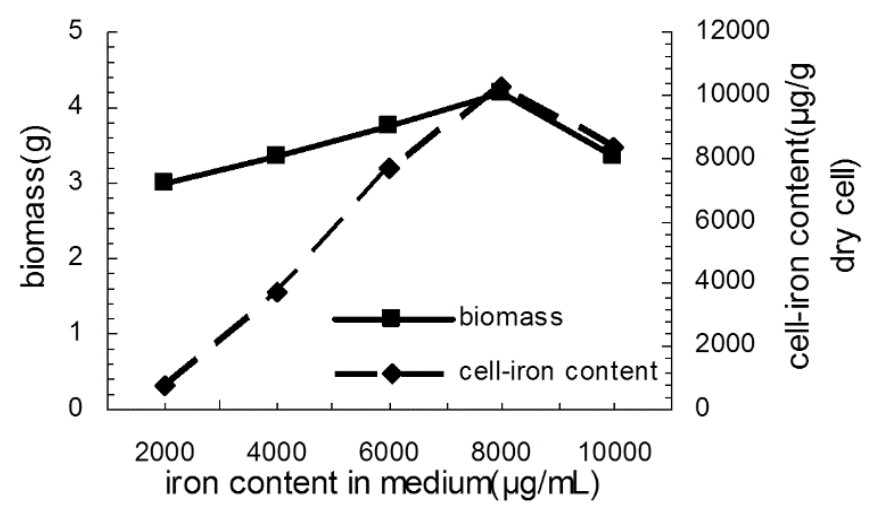

Figure 4. Influence of iron content of the YPD medium on the biomass and iron content of microorganism.

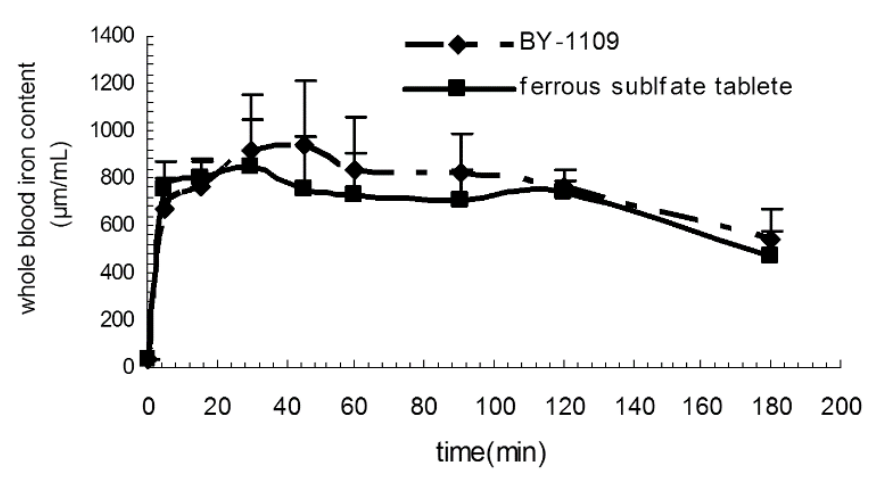

Figure 5. Mean blood concentration-time profiles of No.BY1109 and ferrous sulfate after a signal oral of No.BY1109 and ferrous sulfate to rats at a dose of $10 \mathrm{mg} \mathrm{Fe}(\mathrm{II}) / \mathrm{Kg}$ body weight $(\mathrm{n}=6$; mean \pm standard deviation). 
Table 2. Pharmacokinetic parameters for No.BY1109 and ferrous sulfate in rats after single oral administration of No.BY1109 and Ferrous Sulfate at a dose of $10 \mathrm{mg} \mathrm{Fe}(\mathrm{II}) / \mathrm{Kg}$ body weight. ( $\mathrm{n}=6$; mean \pm standard deviation).

\begin{tabular}{ccrr}
\hline Parameters & Units & \multicolumn{1}{c}{ No.BY1109 } & Ferrous sulfate \\
\hline AUC & $\mathrm{mg} / \mathrm{l} . \mathrm{min}$ & $286360 \pm 0.30$ & $239570 \pm 0.39$ \\
Tmax & $\mathrm{min}$ & $48.07 \pm 0.53$ & $32.28 \pm 0.66$ \\
$\mathrm{Cmax}$ & $\mu \mathrm{g} / \mathrm{ml}$ & $901.27 \pm 0.11$ & $850.92 \pm 0.32$ \\
$\mathrm{~T}_{1 / 2}$ & $\mathrm{~min}$ & $129.06 \pm 0.88$ & $224.53 \pm 0.73$ \\
\hline
\end{tabular}

Table 3. Distribution of iron in organelles of No.BY1109.

\begin{tabular}{ccc}
\hline Organelles $(\mu \mathrm{g}$ Fe/g dry cells) & Added iron & No added iron \\
\hline cell walls & 110.98 & 1.46 \\
Vacuolar & 27.50 & 1.93 \\
Cell membranes & 4.02 & 0.10 \\
mitochondrial & 8.59 & 0.11 \\
cytosolic & 11.59 & 0.32 \\
DNA & 0.23 & 0.04 \\
RNA & 1.45 & 0.03 \\
\hline
\end{tabular}

\section{Discussion}

In this paper, No.BY1109 fungus, which grew well in PDA medium containing $10,000 \mu \mathrm{g} / \mathrm{ml} \mathrm{Fe}(\mathrm{II})$, was isolated from natural environment, and the organically bound iron content from its cells was $10 \mathrm{mg} \mathrm{Fe} / \mathrm{g}$ dry cell. The results of the bioavailability of iron in No.BY1109 fungus compared with those of the ferrous sulfate showed that organically bound iron has better and faster absorption and utilization. The results obtained that there are wild strains in the nature with better ability to enrich iron from the environment than that of S.cerevisiae.

This result is very important in terms of obtaining organically bound iron supplements from natural environment.

Iron is an essential micronutrient in the metabolism of almost all living organisms; however, its deficiency is well documented especially in pregnant women and children. Iron salts as a dietary supplement have low bioavailability and can cause gastrointestinal discomforts. Iron enriched yeasts can provide a supplementation of this micronutrient to the diet because this mineral has a better bioavailability when bonded to yeast cell macromolecules (Gaensly et al. (2011). Pirman \& Orešnik (2012) reported a highly significant $(\mathrm{P}<0.001)$ better bioavailability of iron-enriched yeast biomass, which was on average $36 \%$ higher than the availability of Fe-sulphate-enriched diet. The Findings from the Weng et al. (1989) showed that the $\mathrm{Hb}$ concentration of the yeast iron was sligetly higher than that of ferrous sulfate in Wistar rats . According to Liu et al. (1990), 135 children, aged 18-36 months, were selected from two nurseries and divided into 3 groups for three months. No statistically significant differences were observed in nutrient intake, vitamin loading tests, and serum uric acid (seeking for nuclecic acid metabolite) in each group before and after the experiment. At the end of the experiment, changes in $\mathrm{Hb}, \mathrm{FEP}$, $\mathrm{SF}$ concentration, and FEP/Hb indicated that the iron status of children in the Fe-enriched yeast group was much better than that of children in the ordinary nursery diet groups (Liu et al.,
1990). In the present study, a single oral dose of iron was used to investigate iron absorption and iron clearance. The AUC and Cmax of No.BY1109 after oral administration were both much larger than those of the same dosage of ferrous sulfate tablets. The mean relative bioavailability of $\mathrm{AUC}_{\text {tes }} / \mathrm{AUC}_{\text {ferrous sulfate }}$ was $119.5 \%$ (Figure 5, Table 2), which shows that the bound iron in No.BY1109 was more bioavailable than ferrous sulfate. The results obtained in the present study confirmed that bound to an organic substrate, iron is more efficiently absorbed by organisms. Iron in No. BY1109 may be useful as a functional food ingredient.

Yeast has certain enrichment ability for metal elements. It can convert inorganic iron to organic species and can be used as iron carrier (Yuan et al., 2004). Although S. cerevisiae was used as a trace element vector for organic iron, the tolerance capability of iron for wild type yeast cells is limited, and the wild yeast could grow only in the medium contained $600 \mu \mathrm{g} / \mathrm{ml}$ iron. Therefore, the PDA medium containing $800 \mu \mathrm{g} / \mathrm{mL}$ iron content was used for initial screening of new wild-type high-biomass fungi strains that showed better ability to accumulate high concentration iron than that of $S$. cerevisiae from the natural environment. The No.BY1109 strain was isolated, and its tolerance to iron was almost 20 times higher that of iron yeast. At present, this is the first report on screening of the wild No.BY1109 strain from the natural environment, which grew well on PDA media at an iron concentration of $10,000 \mu \mathrm{g} / \mathrm{mL}$.

Gaensly et al. (2011) and Pirman \& Orešnik (2012) reported that $S$. cerevisiae can enrich iron, and iron content in some iron enriched yeast products reached $8.0 \mathrm{mg} / \mathrm{g}$ dry cells under optimized cultivation conditions. Yuan et al. (2004) showed that the iron content in the iron-enriched strain ZYF-15 reached $25 \mathrm{mg} / \mathrm{g}$ dry cells. In the present study, No.BY1109 tolerated and grew well in the medium containing high iron content, and the iron content in this strain was $10 \mathrm{mg}$ iron/g dry cell. In previous studies for the preparation of iron yeast (Yuan et al., 2004), iron enriched yeast biomass was harvested by centrifugation at $1,500 \times \mathrm{g}$ for $30 \mathrm{~min}$, rinsed twice-third with distilled water, and lyophilized; metal content was then analyzed. However, the present study showed that despite the fact that the fermentation cultures were centrifuged and eluted with distilled water repeatedly (more than seven times), the unbound inorganic iron of the fermentation cultures was not completely eliminated. Results from Nicola et al. (2009) showed that cell walls were washed seven times with deionized and distilled water to remove any unbound inorganic zinc, but the protoplast fragments and the uptake of zinc and the association of zinc was loose and it was readily released to the medium. Therefore, in the present study, an improved dialysis bag method was used to remove iron until inorganic iron was no longer detected. This process was performed to ensure that the combination of organic iron was obtained rather than a mixture of organic and inorganic iron.

The strain BY1109 was identified as Rhodotorula based on cell and colony morphology and 18S rRNA analysis. Special identification of yeast is based mainly on its different abilities to assimilate carbon and nitrogen compounds. In particular, the use of myoinositol as the sole carbon source is the key feature to distinguish between anamorphic yeasts of the genera 
Cryptococcus Vuillemin and Rhodotorula Harrison (Golubev, 2010). This characteristic, which, as a rule, is not shared by ascomycetous yeasts and by basidiomycetous yeasts of other classes, is a fundamental key in yeast identification. The species belonging to the genus Rhodotorula typically do not assimilate myoinositol. It should be noted that such differentiation is becoming less distinct: there are more and more reports on inositol-positive Rhodotorula species (Golubev \& Scorzetti, 2010).We found that the Rhodotorula No.BY1109 was positive for myoinositol assimilation. An rDNA gene sequence analysis and a comparison of its phenotypic properties revealed that the isolates might constitute novel anamorphic species in the Rhodotorula for which the names Rhodotorula langang sp are proposed.

Almost all of the Rhodotorula are non-toxic (Patiño-Vera et al., 2005; Arras et al., 1999). In the present study, the acute oral toxicity test was verified, and Rhodotorula No.BY1109 was safe (Data not shown). Among yeasts, Rhodotorula species is one of main carotenoid-forming microorganisms with predominant synthesis of $\beta$-carotene, torulene and torularhodin (Marova et al., 2012; Davoli et al., 2004). These studies indicate that $\beta$-carotene offers protection against metal-induced lipid oxidation (Darko, 2011). In the present study, the No.BY1109 had the same ability as Rhodotorula to produce pigment and carotenoid (Yang et al., 2011), and the pigment became deep red when the content of iron (Fe II) increased in medium. A possible explanation is based on observations that presence of heavy metals results in the formation of various active oxygen radicals which, in turn, induces the formation of protective carotenoid metabolites that reduce negative behavior of free radicals (Darko, 2011).

The diversity of intracellular organelles and biomolecules provides a wide range of potential binding sites. The results obtained in the present study, show that the iron present in No.BY-1109 cells can be found in different fractions of cells, particularly in cell walls and vacuoles. There was a clear iron accumulation in the cell wall fraction, and the cell wall iron concentration in high iron-grown cells increased almost 75 times (Table 3). The results from Protchenko et al. (2001) and Yuan et al. (2004) confirmed that cell well is an important site of initial biological interaction between cells and external metals ions, and it can facilitate the uptake of iron due to its mannoprotein; however, further studies on the mechanism of mannoprotein and iron interaction are needed.

\section{Conclusion}

In conclusion, in order to make sure if there are wild microorganisms with better ability to tolerate higher concentration iron in the natural environment, high-iron-enriched microorganisms were screened. The results demonstrate that their bioavailability is higher than that of ferrous sulfate. This paper contributes to the search for iron supplement from natural environment.

\section{Acknowledgements}

This research was supported by the program of National Natural Science Foundation of China (No. 31360379) and Gansu province natural science fund (1308RJZA167).

\section{References}

Abbaspour, N., Hurrell, R., \& Kelishadi, R. (2014). Review on iron and its importance for human health. Journal of Research in Medical Sciences, 19(2), 164-174. PMid:24778671

Arras, G., Nicolussi, P., \& Ligios, C. (1999). Non-toxicity of some antifungal yeasts (Pichia guilliermondii, Rhodotorula glutinis and Candida oleophila) in laboratory animals. Annali di Microbiologia Ed Enzimologia, 49, 125-131. Retrieved from http://www.annmicro. unimi.it/full/49/arras_49_125.pdf

Bağ, H., Lale, M., \& Türker, A. R. (1998). Determination of iron and nickel by flame atomic absorption spectrophotometry after preconcentration on Saccharomyces cerevisiae immobilized sepiolite. Talanta, 47(3), 689-696. http://dx.doi.org/10.1016/S0039-9140(98)00104-0

Barnett, J. A., Payne, R. W., \& Yarrow, D. (2000). Yeasts: characteristics and identification. London: Cambridge University Press.

Conrad, M. E., \& Umbreit, J. N. (2000). Iron absorption and transport - an update. American Journal of Hematology, 64(4), 287-298. http://dx.doi.org/10.1002/1096-8652(200008)64:4<287::AIDAJH9>3.0.CO;2-L. PMid:10911382

Dallies, N., François, J., \& Paquet, V. (1998). A new method for quantitative determination of polysaccharides in the yeast cell wall. Application to the cell wall defective mutants of Saccharomyces cerevisiae. Yeast Functional Analysis Reports, 14(14), 1297-1306. http:// dx.doi.org/10.1002/(SICI)1097-0061(1998100)14:14<1297::AIDYEA310>3.0.CO;2-L. PMid:9802208

Darko, M. (2011). Biomass - detection, production and usage. Rijeka Croatia: Intech. Retrieved from http://www.intechopen.com/books/ biomass-detection-production-and-usage.

Davoli, P., Mierau, V., \& Weber, R. W. S. (2004). Carotenoids and fatty acids in red yeasts Sporobolomyces roseus and Rhodotorula glutinis. Applied Biochemistry and Microbiology, 40(4), 460-465. http://dx.doi. org/10.1023/B:ABIM.0000033917.57177.f2. PMid:15455720

Gaensly, F., Wille, G. M. F., Brand, D., \& Bonfim, T. M. B. (2011). Iron enriched Saccharomyces cerevisiae maintains its fermenting power and bakery properties. Food Science and Technology (Campinas.), 31(4), 980-983. http://dx.doi.org/10.1590/S0101-20612011000400025.

Fredricks, D. N., Smith, C., \& Meier, A. (2005). Comparison of six DNA extraction methods for recovery of fungal DNA as assessed by quantitative PCR. Journal of Clinical Microbiology, 43(10), 5122-5128. http://dx.doi.org/10.1128/JCM.43.10.5122-5128.2005. PMid:16207973

Golubev, W. I. (2010). Myo-inositol assimilating new species of Rhodotorula Harrison. Microbiology, 79(6), 862-864. http://dx.doi. org/10.1134/S002626171006024X.

Golubev, W. I., \& Scorzetti, G. (2010). Rhodotorula rosulata sp. nov., Rhodotorula silvestris sp. nov. and Rhodotorula straminea sp. nov., novel myo-inositol-assimilating yeast species in the Microbotryomycetes. International Journal of Systematic and Evolutionary Microbiology, 60(Pt 10), 2501-2506. http://dx.doi.org/10.1099/ijs.0.016303-0. PMid:19915106

Hu, K. (2004). Microbiology experiment. Beijing: Forestry Publishing House.

Khalafallah, A. A., \& Dennis, A. E. (2012). Iron deficiency anaemia in pregnancy and postpartum: pathophysiology and effect of oral versus intravenous iron therapy. Journal of Pregnancy, 2012, 630519. http://dx.doi.org/10.1155/2012/630519. PMid:22792466

Kollár, R., Reinhold, B. B., Petráková, E., Yeh, H. J., Ashwell, G., Drgonová, J., Kapteyn, J. C., Klis, F. M., \& Cabib, E. (1997). Architecture of the yeast cell wall. Beta $(1->6)$-glucan interconnects mannoprotein, beta $(1->) 3$-glucan, and chitin. The Journal of Biological Chemistry, 
272(28), 17762-17775. http://dx.doi.org/10.1074/jbc.272.28.17762. PMid:9211929

Liu, Q. P., Weng, C. Y., \& Xu, D. D. (1990). Evaluation of bioavailability of iron in Fe-enriched yeast II. feeding study in preschool children. Acta Nutrimenta Sinica, 12, 172-177. Retrieved from http://www. cnki.com.cn/Article/CJFDTOTAL-YYXX199002007.htm

Marova, I., Carnecka, M., Halienova, A., Certik, M., Dvorakova, T., \& Haronikova, A. (2012). Use of several waste substrates for carotenoid-rich yeast biomass production. Journal of Environmental Management, 95(Suppl), S338-S342. http://dx.doi.org/10.1016/j. jenvman.2011.06.018. PMid:21741756

Miller, J. L. (2013). Iron deficiency anemia: a common and curable disease. Cold Spring Harbor Perspectives in Medicine, 3(7), pii-a011866. PMID: 23613366

Mutiu, A. I., \& Brandl, C. J. (2005). RNA isolation from yeast using silica matrices. Journal of Biomolecular Techniques, 16(4), 316-317. PMid:16522851

Nelson, N. (1999). Metal ion transporters and homeostasis. The EMBO Journal, 18(16), 4361-4371. http://dx.doi.org/10.1093/ emboj/18.16.4361. PMid:10449402

Nicola, R. D., Hall, N., Bollag, T., Thermogiannis, G., \& Walker, G. M. (2009). Zinc accumulation and utilization by wine yeasts. International Journal of Wine Research, I, 85-94. http://dx.doi. org/10.2147/IJWR.S4570

Pas, M., Piskur, B., Sustaric, M., \& Raspor, P. (2007). Iron enriched yeast biomass - a promising mineral feed supplement. Bioresource Technology, 98(8), 1622-1628. http://dx.doi.org/10.1016/j.biortech.2006.06.002. PMid:16935492

Patiño-Vera, M., Jiménez, B., Balderas, K., Ortiz, M., Allende, R., Carrillo, A., \& Galindo, E. (2005). Pilot-scale production and liquid formulation of Rhodotorula minuta, a potential biocontrol agent of mango anthracnose. Journal of Applied Microbiology, 99(3), 540-550. http://dx.doi.org/10.1111/j.1365-2672.2005.02646.x. PMid:16108795

Pirman, T., \& Orešnik, A. (2012). Fe bioavailability from Fe-enriched yeast biomass in growing rats. Animal, 6(2), 221-226. http://dx.doi. org/10.1017/S1751731111001546. PMid:22436179

Protchenko, O., Ferea, T., Rashford, J., Tiedeman, J., Brown, P. O., Botstein, D., \& Philpott, C. C. (2001). Three cell wall mannoproteins facilitate the uptake of iron in Saccharomyces cerevisiae. The Journal of Biological Chemistry, 276(52), 49244-49250. http://dx.doi. org/10.1074/jbc.M109220200. PMid:11673473

Raguzzi, F., Lesuisse, E., \& Crichton, R. R. (1988). Iron storage in Saccharomyces cerevisiae. FEBS Letters, 231(1), 253-258. http:// dx.doi.org/10.1016/0014-5793(88)80742-7. PMid:3282922

Rayman, M. P. (2004). The use of high-selenium yeast to raise selenium status: how does it measure up? British Journal of Nutrition, 92(4), 557-573. http://dx.doi.org/10.1079/BJN20041251. PMid:15522125

Ruiz-Argüelles, G. J. (2013). Iron deficiency anemia in low- and middleincome countries. Blood, 122(13), 2289. Retrieved from http://www. bloodjournal.org/content/122/13/2289.long?sso-checked=true. http://dx.doi.org/10.1182/blood-2013-05-505297. PMid:24072853

Santiago, P. (2012). Ferrous versus ferric oral iron formulations for the treatment of iron deficiency: a clinical overview. The Scientific World Journal, 2012, 846824. http://dx.doi.org/10.1100/2012/846824. PMid:22654638

Sirdah, M. M., Yaghi, A., \& Yaghi, A. R. (2014). Iron deficiency anemia among kindergarten children living in the marginalized areas of Gaza Strip, Palestine. Revista Brasileira de Hematologia e Hemoterapia, 36(2), 132-138. http://dx.doi.org/10.5581/1516-8484.20140030

Stehlik-Tomas, V., Zetic, V. G., Stanzer, D., Grba, S., \& Vahcic, N. (2004). Zinc, copper and manganese enrichment in yeast Saccharomyces cerevisae. Food Technology and Biotechnology, 42, 115-120. Retrieved from http://hrcak.srce.hr/index.php?show=clanak\&id_clanak_ jezik $=163285$

Tompkins, T. A., Renard, N. E., \& Kiuchi, A. (2007). Clinical evaluation of the bioavailability of zinc-enriched yeast and zinc gluconate in healthy volunteers. Biological Trace Element Research, 120(1-3), 2835. http://dx.doi.org/10.1007/s12011-007-0072-2. PMid:17916952

Wang, J., \& Pantopoulos, K. (2011). Regulation of cellular iron metabolism. The Biochemical Journal, 434(3), 365-381. http://dx.doi.org/10.1042/ BJ20101825. PMid:21348856

Weng, C. Y., W., Liu, Q. P., \& Xu, D. D. (1989). Evaluation of bioavailability of iron in Fe-enriched yeast I. prophylactic assay in rats. Acta Nutrimenta Sinica, 11, 311-318. Retrieved from http://www.cnki. com.cn/Article/CJFDTotal-YYXX198904001.htm

Wysocki, R., \& Tamás, M. J. (2010). How Saccharomyces cerevisiae copes with toxic metals and metalloids. FEMS Microbiology Reviews, 34(6), 925-951. http://dx.doi.org/10.1111/j.1574-6976.2010.00217.x. PMid:20374295

Yamada, Y., Makimura, K., Merhendi, H., Ueda, K., Nishiyama, Y., Yamaguchi, H., \& Osumi, M. (2002). Comparison of different methods for extraction of mitochondrial DNA from human pathogenic yeasts. Japanese Journal of Infectious Diseases, 55(4), 122-125. Retrieved from http://www.researchgate.net/publication/11059967. PMid:12403909

Yamaguchi-Iwai, Y., Dancis, A., \& Klausner, R. D. (1995). AFT1: a mediator of iron regulated transcriptional control in Saccharomyces cerevisiae. The EMBO Journal, 14(6), 1231-1239. Retrieved from http:// www.ncbi.nlm.nih.gov/pmc/articles/PMC398200. PMid:7720713

Yang, J., Tan, H., \& Yang, R. (2011). Astaxanthin production by Phaffia rhodozyma fermentation of cassava residues substrate. Agricultural Engineering International: CIGR Journal, 13(2), 1-6. Retrieved from http://www.cigrjournal.org/index.php/Ejounral/ article/ viewFile/1847/1408

Yuan, Y., Guo, X., He, X., Zhang, B., \& Liu, S. (2004). Construction of a high-biomass, iron-enriched yeast strain and study on distribution of iron in the cells of Saccharomyces cerevisiae. Biotechnology Letters, 26(4), 311-315. http://dx.doi.org/10.1023/B:BILE.0000015449.30186.90. PMid:15055767 